\title{
On the Importance of Establishment of A New Piano Teaching System in Multi-cultural Context for Improving Students' Innovation Ability
}

\author{
Xiaoxia Zhang \\ Hebei North University, Zhangjiakou, 075000,China
}

Keywords: multi-cultural, piano teaching, innovation, potential, interest

\begin{abstract}
Piano teaching in multi-cultural context can not only promote spread of popular culture, but also attract different piano music audience and thus push diversified development of piano music. Piano teaching shall follow principle of diversification, establish new teaching concepts, use new teaching models, expand teaching content, build a diversified teaching system, discover students' potential, stimulate students' initiative, and cultivate creative thinking and innovation ability in terms of music.

With the spread and promotion of piano around the world, piano is gradually combined with local music, which greatly enriches the connotation of music, leads to the occurrence of piano music with different characteristics, and piano music has different audience. In this multi-cultural context, piano teaching shall also have diversified concepts. For example, teaching content of piano major in higher conservatories of music has the center of traditional music supplemented by modern works and national styles, and emphasizes artistry. Colleges shall build a new piano teaching system, enrich course content and the connotation of piano teaching, make clear of talent training direction, and promote cultivation of students' creative thinking and innovation ability.
\end{abstract}

\section{Establish a multi-cultural view and discover students’ potential}

Few students majoring in piano in conservatories of music have piano foundation, and most of students just know some simple knowledge about piano. From a physiological perspective, bones of students' fingers have been basically shaped with low flexibility, and students can hardly complete requirements of multi-cultural context for piano teaching within a short time as there are few class hours, which makes piano teaching very difficult. Thus, a piano teaching way that complies with multi-cultural context shall be explored, in order to discover students' potential, improve teaching efficiency and quality, and train piano talents of the new era.

It is believed that piano teaching shall be taught since childhood, while adults have missed the best stage of physical function, can hardly have great improvement, feel very difficult to master piano playing skills and encounter many barriers while learning. Thus, we shall establish a multi-cultural view, respect and understand each student, teach in accordance with students' characteristics, stimulate students' enthusiasm and initiative for learning piano, and discover potential of each student. College students have completed physical development, and have great advantages in learning skills such as pedal and playing octave etc. Therefore, teachers shall firstly regulate playing skills and methods, and improve students' ability to read music score, and train students' piano playing level step by step. Meanwhile, college students have strong verbal comprehension, self-discipline, self-consciousness and self-study ability, and can understand some complex concepts correctly, know their learning objectives clearly, supervise themselves, and complete learning tasks. Meanwhile, they have better knowledge summarizing ability and abstract thinking ability than young students, and could learn new knowledge initiatively. So, students majoring in piano have more advantages in spite of weak foundation. Teachers shall begin with basic skills, train students' basic playing methods and skills, combine intensive practice with extensive practice, and have strict requirements for important music in terms of playing methods and music processing etc, so that students could digest knowledge in intensive practice. In terms of extensive practice, broaden students' horizon, reflect multi-cultural context, and let students know more piano music with different styles and nationalities, apply theoretical knowledge to practice and realize deepening and sublimation of knowledge. 
Piano teaching has a multi-cultural view, broadens students' horizon, lets students find their favorite piano music, stimulates their learning interest and curiosity, and improves teaching efficiency and quality. With a multi-cultural view, teachers could observe each student carefully, discover students' potential, teach in accordance with students' aptitude, and promote cultivation of students' potential. At present, multi-cultural view has been reflected in piano teaching of some conservatories of music. For example, Sichuan Conservatory of Music and Xinghai Conservatory of Music have pop music major, and piano major mainly teaches piano playing of pop music and Jazz to train instrumental performers and pop musicians.

\section{Use new piano teaching models and train creative thinking}

Multi-cultural context requires piano teaching to reflect combination of multiple teaching models, respect and understand each student, emphasize equal communication and activities among students, mobilize each student's enthusiasm and train creative thinking. Although piano playing skills are important, pure skills are just the foundation of playing. The life of art lies in creation, and players shall recreate works after possessing superb skills, and add their own thoughts and creativity, so that piano playing has artistic appeal and gets rid of rigid low level. The foundation of training creative thinking is students' understanding of piano works, as they could only remember after understanding and then interpret and recreate emotionally.

A pianist has said that: piano teachers shall be good at stimulating students' learning interest and make students develop good habits of piano practice and practice happily. When students have not a strong desire to practice piano, they can hardly achieve good results. A good teacher could make students love practicing piano, to yield twice the result with half the effort. Therefore, in piano teaching, teachers shall learn to use different teaching models, simulate students' interest in learning, make students love practicing piano, and train their creative thinking. For example, teachers could let students be masters of piano through interactive teaching, and select lots of music from a vast number of piano works, so as to enrich classroom teaching content and let students find their favorite music, practice their favorite music initiatively, understand spiritual connotation and emotions of music while practicing, and then add their own feelings and recreate. Of course, teachers shall also encourage and lead students to observe music in life during teaching activities, listen and watch more, and discover their favorite music.

Constructivism teaching concept tells us that: learning is an internalization process, instead of simple knowledge memory and spread, and teaching shall be student-oriented. In piano teaching, exploratory teaching model can help guide students to find learning methods that suit for them and improve learning efficiency. This teaching model can stimulate students' initiative in active exploration and assiduous study, instead of simply mechanical imitation, and can help train students' music creative thinking. Exploratory teaching model allows students to experience the fun of innovation in deep and independent exploratory activities, stimulate innovation desire and train creative thinking. For example, when learning Waltz of Chopin, teachers could let students obtain materials related to Waltz in spare time, and then discuss about a certain item such as genre in groups in classes, know about all aspects of this genre, and appreciate Waltz of Straus, so that they could have a more intuitive understanding of this genre and introduce learning content. Through such independent and exploratory activities, students could have a deeper understanding of Waltz under inspiration and guidance of teachers, master playing methods and learn music expression.

Context is the combination of objective natural world and people's psychological activities, and good educational context can enhance communication between teachers and students and help sprout and development of creativity. The key of training students' innovation ability in teaching lies in a creative activity context for students to stimulate their learning interest and desire. Piano teaching shall emphasize artistry of context and learning of piano knowledge in context. Before learning a new piece of music, know about its cultural background and reflected content, create appropriate educational context, improve students' aesthetic sentiment and emotional experience, interpret musical works better, and train students' innovation ability. Piano teaching has very strong practicality, not only includes teaching of piano knowledge and training of music skills, but also 
reflects musical feelings generated because of interaction between piano and students' psychology \& physiology, abandons traditional teaching methods, reflects student-oriented thought, guides students to think about problems, and makes students' learning initiative, exploratory, innovative and individualized. Classroom teaching changes from traditionally passive into multi-dimensional, interactive, initiative and efficient. Penetrate actively into knowledge of other disciplines, so that students could know about social function and status of piano according to existing life experience and knowledge, feel and express music from the perspective of social life, improve music appreciation ability, improve learning interest and train creative thinking.

\section{Expand piano teaching content and train students' innovation ability}

In multi-cultural context, piano teaching content shall meet students' need to know about world music inheriting traditions. Piano teaching in many colleges mainly involves European classic music works, which don't cover all of world piano works even if they are classic piano music and required works in piano teaching. Therefore, piano teaching shall have a complete course system, realize horizontal and longitudinal extension, add classic piano music works of Baroque, modern piano works, national music piano works and Jazz piano works etc, broaden students' horizon, add piano culture, give play to students' initiative, stimulate students' interest in learning piano music, cultivate piano feelings, and enhance recreation interest and innovation ability. In multi-cultural context, piano teaching shows the complete perspective of world piano culture, and shall attach importance to Chinese piano works, so that students could understand emotions and spirit of piano works from a cultural perspective, gradually train their cross-cultural and innovation ability, and enhance patriotic feelings and national integration. Students could understand characteristics, styles, aesthetics and culture of Chinese piano music while knowing about world piano music, compare comprehensively between Chinese and western piano music, and thus strengthen communication between Chinese and western culture, so that students could have a more in-depth and complete understanding of western culture and create better piano music.

Piano teaching in Chinese conservatories of music often ignores students' innovation ability, attaches too much importance to teaching of skills, and results in inadequate innovation ability and practical ability of students. Thus, impromptu accompaniment teaching content shall be added to course system, and different teaching models shall be taken in different courses, such as: collective teaching of keyboard harmony and texture writing; and one-to-one guided teaching for homework correction, so that students could play their assignment with keyboard directly. Teachers carry out key demonstration in collective classes, so that students could enhance their impromptu accompaniment ability while knowing about keyboard harmony. In addition, to train students' innovation ability, teachers shall enrich the content of piano music appreciation classes, give play to advantages of collective teaching model, and let students analyze music genre, musical form and emotions etc in groups, have a deep understanding of piano knowledge in group discussion, communication and doubts, and improve their appreciation ability of piano works and overall art accomplishment.

Practice shows that training of innovation ability not only comes from problem exploration and study, but also benefits from profound basic knowledge and broad horizon. New piano teaching system shall expand teaching content, and combine culture and music theoretical knowledge with piano playing skills, so that students could not only play and sing, but also have impromptu accompaniment and singing while playing, learn to convey feelings with piano based on understanding of piano culture, and give good play to emotion transfer function of music language.

Finally, establishment of new piano teaching system shall also involve improvement and components of evaluation system, and shall not be limited to evaluation of piano knowledge and playing skills, but also attach importance to evaluation of humanistic and artistic accomplishment and learning emotions etc, combine many evaluation methods, and evaluate items selected by students that they are good at, so as to meet students' desire to show off, discover students' potential, enhance students' piano music experience, improve appreciation ability and broaden horizon of piano music. A scientific evaluation system can help stimulate students' learning interest and desire, 
develop team spirit, promote intellectual development and cultivation of psychological qualities, and improve innovation ability.

\section{Conclusions}

Piano teaching is a subtle process, and can help develop intelligence, strong will and innovation ability, improve appreciation ability, and finally enlighten students' wisdom and purify soul. Therefore, piano teaching shall be people-oriented, start from students and their learning interests, cultivate students' taste, and develop students' perfect personality, rich imagination, superb appreciation ability and innovation ability of piano works in strong piano cultural atmosphere.

In multi-cultural context, piano teaching system shall reflect multi-cultural characteristics from perspectives of teaching concept, teaching model, teaching method, teaching content and teachers' ability etc, bring students rich multi-cultural piano teaching, broaden students' horizon, and let students find their favorite piano music, master piano playing skills, practice piano pleasantly, add their emotions, recreate piano works, train creative thinking ability and innovation ability, and become new generations of piano innovation talents. Therefore, colleges shall carry out teaching system reform initiatively according to reality of teaching and students, establish a new teaching system, and focus on training students' innovation ability.

\section{References}

[1] Zhang Nan. Adjustment and Innovation: The Construction of Piano Teaching System in Normal College [J]. Heilongjiang Researches on Higher Education, 2008 (3): 143-145.

[2] Li Hui. Thoughts on Establishment of College Digital Piano Collective Teaching System [J]. Hunan Middle School Physics · Cutting-Edge Education, 2009 (8): 125-126.

[3] Wang Xiaokun. Study on Piano Teaching Reform in Higher Normal Universities in Multi-cultural Educational Context [J]. Journal of Henan Normal University (Philosophy and Social Sciences), 2010, 37 (5): 252-253.

[4] Zhang Xuna. Piano Teaching System Reform and Teaching Assumptions of Higher Normal Universities [J]. China Education Innovation Herald, 2008 (32): 186-187.

[5] Luo Wei. On Training of Creative Music Thinking in Children's Piano Teaching [J]. Huangzhong (Journal of Wuhan Conservatory of Music), 2006 (z1): 185-187.

[6] Chen Yiqun. Piano Teaching Model in Higher Vocational Colleges in Multi-cultural Context [J]. Hundred Schools in Arts, 2011 (z2): 416-418. 